\title{
DESIGUALDADE SOCIAL E POBREZA: CONTEXTO DE VIDA E DE SOBREVIVÊNCIA
}

\author{
Antonio Euzébios Filho \\ Raquel Souza Lobo Guzzo \\ Pontifícia Universidade Católica de Campinas, Campinas, Brasil
}

\begin{abstract}
RESUMO: O objetivo desta pesquisa foi compreender como um jovem de 22 anos retrata sua condição de vida, as razões que explicam a desigualdade social e quais perspectivas para melhorias futuras. Os resultados mostram que a desigualdade social foi refletida a partir das suas próprias experiências, principalmente, pelas diferenças econômicas observadas em seu cotidiano. Sobre o futuro, limita-se aos aspectos imediatos da sua realidade. Para o participante, a conquista de uma vida melhor é uma tarefa complexa, devido às dificuldades econômicas que se impõem no dia a dia, e cabe ao sujeito superá-las por meio da ação individual, não necessariamente coletiva.
\end{abstract}

PALAVRAS-CHAVE: desigualdade social; pobreza; ideologia; relações sociais.

\section{SOCIAL INEQUALITY AND POVERTY: LIFE CONTEXT AND SURVIVAL}

ABSTRACT: The main goal of this research was to understand how a young man, 22 years old, describes his life condition, the reasons that explain the social inequality and what are the perspectives to improve his life. The results show that social inequality is referenced by his own experience, specially, by economic differences observed. About the future, he limits the reflection to immediate aspects of his reality. The conquest of a better life is a complex task, essentially an individual task.

KEYWORDS: social inequality; poverty; ideology; social relations.

\section{Introdução}

Este artigo é fragmento da dissertação de mestrado de um dos autores ${ }^{1}$, cujos objetivos foram (a) conhecer como pessoas caracterizaram a si próprias enquanto membros de um determinado segmento social e econômico; (b) conhecer a visão dos sujeitos sobre as causas da desigualdade social, a quem eles atribuiriam responsabilidades: a si próprios, aos indivíduos isoladamente, à sociedade ou a uma conjunção de fatores? (c) refletir sobre uma experiência marcante em que puderam vivenciar a desigualdade social, de uma forma ou de outra, no contexto de suas vidas ou do trabalho; e, por fim, (d) entender como os participantes desta pesquisa elaboraram seus projetos futuros e como pensaram alternativas para redução da desigualdade social (Euzébios Filho, 2007).

Para a dissertação de mestrado (Euzébios Filho, 2007) foram entrevistadas quatro pessoas: uma assistente social, uma psicóloga e dois pais de alunos de uma escola pública onde o pesquisador atua. Foram realizadas entrevistas individuais, norteadas com questões que buscaram abranger os objetivos acima mencionados. Em um primeiro momento, as entrevistas foram analisadas separadamente, depois as informações foram aglutinadas em torno de categorias mais amplas, que puderam sintetizar as temáticas surgidas em cada entrevista (Euzébios Filho, 2007).

As entrevistas foram estruturadas com base nas questões de uma pesquisa que procurou investigar: o que determinadas pessoas pensam sobre a vida que vivem? O que pensam sobre a realidade em que estão inseridas? E sobre a desigualdade social? Quais são as causas e consequências deste quadro social em que vivemos? Como este fenômeno interfere na vida dos participantes desta pesquisa?

A partir destas questões, abriu-se caminho para compreender que, em termos socioeconômicos, a psicóloga e a assistente social caracterizaram-se enquanto membros de um segmento médio da população. Os pais dos alunos caracterizaram-se, por sua vez, como pobres. A desigualdade social é caracterizada a partir de diferentes fatores, como a forma de viver, de morar, os relacionamentos, a forma de se vestir, de lidar com a vida, etc. Todavia, para os quatro participantes, o fator predominante que justifica (e não simplesmente explica) a existência da desigualdade social é o indivíduo isolado - aquele sujeito que não planeja seu futuro, sujeito irresponsável e desmotivado, não dotado de uma "força interior", como disse uma das participantes. Os participantes não apresentaram grandes perspectivas de 
mudança social, tanto no âmbito local quanto estrutural. Pelo que relataram, parecem acreditar, ainda que com reservas, somente em mudanças imediatas, mas acreditam que a falta de mobilização da população é um fator preponderante da não garantia da dignidade e dos direitos fundamentais de homens e mulheres.

Estes resultados são consequência de uma síntese das quatro entrevistas realizadas para a referida dissertação de mestrado, porém é importante destacar que, para este artigo, selecionamos a análise de apenas uma delas (a de um pai de uma aluna da escola mencionada), por considerar que revela com mais agudeza o fenômeno da desigualdade social, na visão de um jovem negro sobre seu cotidiano de vida e de trabalho. É um relato contundente, que expressa como o participante observa sua realidade e reflete sobre possíveis caminhos para alcançar uma vida melhor.

Antes da uma análise minuciosa desta entrevista e explicitação dos procedimentos metodológicos empregados neste estudo, apresentamos alguns pressupostos teóricos que versam sobre a concepção de sujeito adotada pelos autores para, posteriormente, dirigir uma crítica à noção naturalizada da história e da própria essência humana, enquadrando esta concepção no marco de um fenômeno político-ideológico, cujo impacto pode ser negativo sobre a visão que as pessoas têm dos outros, de si próprios e da desigualdade social.

\section{Sujeito e Essência Humana: Uma Perspectiva Marxista}

Baseados nos preceitos do materialismo histórico e dialético, procuramos mostrar como Marx concebia o ser social e como lidou com o conceito de essência humana. Marx buscou os fundamentos da essência humana na historicidade do ser. Para ele, a condição social do homem é imanente, portanto, o primeiro atributo da essência humana. Por essa razão, não é possível compreender o sujeito fora da História, afirmação esta que revela uma concepção fundada no princípio da unidade dialética entre subjetividade e objetividade, entre sujeito e objeto, entre consciência e realidade. Essa unidade se processa como Marx (1845/2004b) compreende na VI tese sobre Feuerbach, a partir de uma substância concreta, de uma essência que é resultado de um conjunto de relações sociais. É importante acrescentar a essa passagem (e isso fica evidente no desenvolvimento teórico de Marx) que as relações sociais não são uma entidade soberana, que se impõem frente aos indivíduos isolados, mas sim parte da constituição individual do ser social (Costa, 2005; Lowy, 1989; Meszáros, 2006; Tonet, 2005).

Para Marx (1845/2004b), a essência humana só pode ser captada dentro do campo concreto das relações humanas, considerando aí as ações intencionais dos sujeitos sobre a realidade, que é o que determina a continuidade ou descontinuidade de um processo histórico, lembrando que, quando Marx falava de essência, ele não se referia necessariamente à individualidade, embora $\mathrm{o}$ conjunto das relações sociais seja requisito para compreensão do sujeito particular (Meszáros, 2006).

Embora a grande contribuição de Marx tenha sido reconhecer um sistema complexo, que compreende a essência e a existência humanas como duas dimensões de uma mesma realidade, Meszáros, (2006) e Séve (1979a, 1979b, 1979c) reconhecem que Marx faz uma distinção entre o conceito de essência humana (que não é uma abstração inerente ao indivíduo isolado) e o conceito de individualidade (que é parte de um conjunto de relações sociais, mas que, todavia, opera conscientemente sobre a realidade) $)^{2}$.

A existência e a essência humanas são constituídas a partir de um campo concreto de possibilidades determinado por um conjunto de relações sociais - o sujeito ao nascer depara-se com uma realidade que está posta, mas que não é imutável. Nesta perspectiva, a ação humana assume uma dimensão material e histórica, ao mesmo tempo em que consciente e singular (Meszáros, 2006).

Com isso, Meszáros (2006) e Tonet (2005) afirmam que toda ação humana é conformada no marco da teleologia e da causalidade, isto é, no marco de uma tensão gerada pela ação intencional do sujeito, uma ação diante das possibilidades concretas, o que torna, portanto, nossa liberdade um fato objetivo e socialmente referenciado.

O campo de possibilidades, assim como a liberdade humana passam a ser compreendidos a partir da condição concreta de vida de um sujeito ou de grupo social, o que engloba uma análise sobre um dado processo histórico de automediação social (efetuada primordialmente pela relação sujeito-sociedade) e pelo reconhecimento de uma relação imanente do homem com a natureza e vice-versa (Meszáros, 2006). De toda forma, o campo de possibilidades pode ser expandido por meio da capacidade reflexiva e criativa dos sujeitos particulares, mas ele é definido, em primeira instância, pelo processo produtivo que, para Marx, é o que determina um modo de organização social.

Pela via do trabalho, Marx compreende o processo produtivo como um processo de autoconstrução do homem pelo homem ${ }^{3}$, o que, de fato, representa o marco ontológico da análise marxiana. Por isso Séve (1979a) sustenta que um quadro geral, que caracteriza qualquer análise de base marxista, consiste em discutir "as relações sociais que constituem a essência real das relações entre as coisas" (p. 139). As relações sociais tomam corpo a partir das relações entre as coisas, mas estas últimas, acima de tudo, são relações entre indivíduos concretos que vivem, sentem e se apropriam conscientemente da realidade em que vivem. 
Por tudo o que foi colocado, Meszáros (2006) compreende a proposta de essência em Marx como parte de um sistema teórico complexo, cuja preocupação é analisar o social não apenas como limitação que se impõe ao indivíduo, mas como possibilidade deste constituir sua individualidade. O avanço filosófico de Marx reside exatamente em uma noção de essência humana que é posta em movimento pela "autoconstrução do homem pelo homem" e que reconhece, no próprio sujeito, a capacidade de modificar a realidade posta.

\section{Ideologia e Individualização dos Fenômenos Sociais}

A força da ideologia reside, justamente, em sua capacidade de conferir um sentido sobre algo, de modo que ele seja eficiente para acirrar ou sustentar as relações de poder (Eagleton, 1997; Guareschi, 1996). Em outras palavras, podemos afirmar que a ideologia possui originalmente uma natureza de classe, ao passo que a manifestação ideológica serve, por diferentes vias e intensidades, como instrumento político para dominação social (Dobles, 1999).

Com o objetivo de sustentar uma relação entre classes, ao tratar da essência humana sem considerar sua dimensão histórica, a ideologia liberal fomenta, de diferentes maneiras, uma visão naturalizada do mundo dos homens: as relações mercantis são tomadas como resultado de um aperfeiçoamento gradual da essência humana, naturalmente competitiva e mesquinha, que se desenvolveu, ao longo do tempo, ao ponto de estas "características naturais" do humano serem controladas e civilizadas - a exemplo da sociedade burguesa (Tonet, 2002, 2005). Esta concepção liberal reconhece uma essência humana predeterminada, cuja real expressão se dá com o desenvolvimento do próprio capitalismo (Meszáros, 2006).

O pensamento liberal assume uma finalidade prática: fazer com que o sujeito se enxergue como espectador da realidade, ocultando as origens das mazelas sociais (Meszáros, 2006) e direcionando para os oprimidos a responsabilidade por viverem da maneira como vivem. Logo, estes são taxados como a "escória da humanidade", em outras palavras, é o sujeito sem renda e sem propriedade, o culpado pela desigualdade social.

No período atual do capitalismo, um dos mecanismos ideológicos utilizado para ocultar a natureza destrutiva do sistema social vigente é responsabilizar, exclusivamente, o indivíduo pelo seu "fracasso" ou pelo "sucesso". Ambos são medidos pela capacidade do sujeito agir de acordo com sua própria essência, ou seja, quanto mais individualista e egoísta ele for, mais estará se adaptando à ordem "natural" das coisas e mais "sucesso" obterá. Ademais, esta cosmovisão individualista (nas palavras de Guareschi, 2005) embute no imaginário popular uma noção sobre "sucesso", que deve ser alcançado a partir do esforço individual, de um sujeito supostamente auto-suficiente.

O pobre, assim, é visto por essa mesma sociedade capitalista, que reifica as relações humanas e mercantiliza todas as esferas da vida cotidiana, como um perdedor, um ser desvalorizado socialmente, um ser desprovido de competências individuais para alcançar um determinado patamar financeiro (Freire, 1989; Guareschi, 2005). Essa análise do segmento mais pobre da população reflete uma visão condicionada pelos traços mais marcantes da ideologia burguesa, difundidos largamente na sociedade (pela televisão, pelos programas assistenciais, escolas, etc.), tais como: (a) culpabilização dos indivíduos pelos seus fracassos (quando a sociedade justifica o fracasso por uma suposta deficiência moral que está presente, por excelência, nas famílias mais pobres); (b) discurso da competência (no caso de o pobre ser considerado, por natureza, um indivíduo menos competente do que o rico, no que diz respeito à obtenção de um determinado padrão de vida); (c) associação da pobreza à violência (o pobre como ser essencialmente rude, bruto e violento) (Coimbra, 2001; Costa, 2005; Euzébios Filho \& Guzzo, 2007; Martín-Baró, 1998; Patto, 1997).

A ideologia dominante contribui para difusão de uma imagem negativa do sujeito sobre si mesmo e os outros. Ela constitui um determinado padrão de relacionamento social que se estabelece com base em estereótipos, elaborados dentro de um determinado processo comunicativo cuja base é objetiva - a dominação política e econômica de uma classe sobre a outra (Alfaro, 1993; Martín-Baró, 2000; Patto, 1993, 1997).

A ideologia de culpabilização do pobre baseia-se na elaboração e propagação de estereótipos que, para González Rey e Mitjáns (1989), representam normas e valores caracterizados pela baixa mobilidade e baixo nível de operacionalização da personalidade, ou seja, pela incapacidade momentânea de o sujeito integrar as informações e transcender os processos simbólicos que o impedem de atualizar seus pensamentos, por meio de uma reflexão crítica a respeito de um determinado aspecto de sua vida. A imersão da consciência em um nível mais imediato da realidade faz com que as informações apareçam de maneira fragmentada, associada a elevadas cargas emocionais que exercem diferentes tipos de função psicológica, geralmente associados ao senso comum.

É certo que, para que ela seja efetiva, a ideologia dominante toma como base uma realidade objetiva, uma vez que a melhoria do poder aquisitivo não é uma regra, e sim uma exceção (Eagleton, 1997). Todavia, a ideologia de culpabilização do pobre não serve para explicar as limitações do modelo capitalista, mas para justificar a desigualdade social a partir de um suposto déficit in- 
dividual, que não é, necessariamente, comum a todos os homens, mas ele abarca, sem dúvida, nesta perspectiva, uma maioria desprivilegiada da população, o que contribui para reforçar a consciência de que o sistema social e a as relações capitalistas são as únicas alternativas para o bem-estar da sociedade e que, portanto, são culpabilizados aqueles que não conseguem adaptar-se à ordem "natural" das coisas (Augoustinos, 1999; Tonet, 2002, 2005).

Diante dessa perda do sentido histórico da desigualdade social, questiona-se: será que as pessoas são fisgadas por estas tramas ideológicas, que responsabilizam somente o indivíduo pelo "sucesso" ou pelo "fracasso"?

A partir dessas preocupações passaremos, neste momento, a discutir como a desigualdade social é percebida pelo sujeito desta pesquisa, como ele compreende, à sua maneira, as relações sociais no capitalismo e qual papel ele acha que pode cumprir para mudar ou manter suas condições de vida.

\section{Método}

\section{Abordagem Teórico-Metodológica}

A análise das informações foi realizada com base no referencial da epistemologia qualitativa proposto por González Rey (1998, 1999, 2003, 2005). Esse referencial está fundamentado em uma concepção sobre a subjetividade humana, uma noção que enfatiza o caráter dinâmico das relações sociais, marcadas por um processo comunicativo integrado às motivações e aos interesses dos sujeitos particulares. Nesse sentido, o autor enfatiza o diálogo como uma importante ferramenta para captar a processualidade das informações e para revelar a riqueza do pensamento social e, ao mesmo tempo, particular dos sujeitos.

Para Konder (1981, 2003), o diálogo representa uma das vias de acesso para captar a natureza dialética dos fenômenos sociais. Por meio dele é possível apreender parte das contradições expressas no marco da tensão que se estabelece entre subjetividade e objetividade.

A contradição é o que gera mobilidade para o pensamento e ela serve tanto para estruturá-lo como para externalizá-lo (González Rey, 1998). O pensamento se estrutura a partir do diálogo, da relação entre os sujeitos. Pelo diálogo é que se pode conhecer de uma maneira privilegiada (isto é, de maneira a buscar identidades e contradições no conteúdo das informações) o que um sujeito pensa e reflete sobre determinado assunto.

A perspectiva metodológica adotada insere-se no campo da dialética marxista, assim, as entrevistas abertas, capazes de gerar um diálogo, devem proporcionar o aparecimento de aspectos contraditórios que caracterizam a tensão entre o concreto e sua significação subjetiva. Com base nesses preceitos teórico-metodológicos, a entrevista realizada, apesar de norteada por questões semiestruturadas, relacionadas aos objetivos deste estudo, não impediu a livre expressão do sujeito e o diálogo aberto entre pesquisador e participante.

Esse procedimento pode ser enquadrado naquilo que García, Giuliani e Wiesenfeld (2002) compreendem por "entrevista em profundidade". Segundo os autores, esse tipo de entrevista marca uma tradição qualitativa nas ciências sociais que prima pelo diálogo com o entrevistado, dentro de um campo descontraído, em que se propicia a expressão contínua e aprofundada sobre um tema de interesse.

\section{Procedimentos de Análise do Conteúdo das Informações}

A entrevista foi gravada e transcrita fielmente para que se pudesse captar a integralidade daquilo que foi expresso pelo participante. A leitura e a releitura dessa entrevista foram realizadas procurando estabelecer conexões, mediações e contradições entre os diferentes argumentos do sujeito entrevistado (Yamamoto, 1994). Procurou-se identificar semelhanças dentre os argumentos a partir de uma análise das contradições. Nesse sentido, foram identificadas as determinações fundamentais e, posteriormente, as determinações secundárias que caracterizaram o conteúdo das informações (Jacques, 1993).

As determinações fundamentais foram estabelecidas pela identificação de informações que convergiram e que geraram sentido a respeito de um determinado assunto, trata-se daquelas informações que tornaram explícitas a visão do sujeito acerca de um tema específico. Essa discriminação possibilitou a demarcação de fronteiras temáticas, elaboradas a partir do reconhecimento de informações comuns, que surgiram no momento da entrevista. Foi utilizado, portanto, um método comparativo de análise, que se prestou a compreender as semelhanças e, com isso, as disparidades das informações trazidas pelo participante. As determinações secundárias dizem respeito ao conteúdo de uma temática, trata-se das contradições e da consistência daqueles argumentos que giram em torno de um determinado assunto.

A convergência de ideias sobre um determinado tema possibilitou a elaboração de unidades de sentido (Jacques, 1993; Konder, 1981). Essas unidades dizem respeito às categorias de análise, que resultaram da depuração das informações realizada a partir da visão dos pesquisadores e também com base no arcabouço teórico adotado neste trabalho.

A identificação das categorias revela uma similitude de determinadas informações, que foi captada pela leitura que os pesquisadores realizaram do conteúdo da entrevista. A análise dessas categorias representa, por sua vez, a maneira como o participante se expressou a respeito de um tema, se de maneira coerente ou contra- 
ditória em relação ao conjunto de argumentos gerados no momento da entrevista.

\section{Contato com o Participante}

Por meio de um projeto de extensão, financiado pelo CNPq e denominado 'Risco à Proteção: uma intervenção preventiva na comunidade' (Guzzo, 2004), desenvolvemos atividades em uma unidade territorial marcada pela desigualdade social, situada na região Leste da cidade de Campinas. Nesse contexto, a intervenção da equipe de psicologia (que envolve estudantes e profissionais em psicologia) ocorre em uma escola municipal de educação infantil da região.

A inserção nessa escola municipal abriu possibilidades de contato com os moradores da região e, com isso, também a possibilidade de acompanhar uma atividade que estava sendo desenvolvida em outra escola da região - justamente onde o participante desta pesquisa estudava (cujo referido projeto não desenvolveu atividades regulares). Nesse contexto, o participante foi identificado na condição de pai de uma aluna da escola onde o projeto 'Risco à Proteção' desenvolve suas atividades. A partir de então foi iniciado um diálogo sobre as condições das escolas públicas da região, sobre as condições de vida das pessoas que vivem ao redor das escolas nos bairros populares e sobre sua própria vida.

\section{Caracterização do Participante}

O participante é um jovem negro de 22 anos, aluno de uma escola estadual e pai de uma criança que estuda em uma escola pública de educação infantil. Ele é solteiro e vive com a avó materna e mora (desde que nasceu) em um bairro popular próximo às referidas instituições de ensino. Hoje ele cursa o terceiro ano do ensino médio na mesma escola estadual da região.

Foram várias as ocasiões em que pudemos dialogar livremente com o participante. Nessas conversas ele expressou insatisfação a respeito das suas condições de trabalho e de vida. Contou que havia saído da prisão há poucos meses e que isto o atormentava. Relatou as transformações que ocorreram na sua vida. Disse que a notícia de que teria uma filha deu-se na mesma época em que foi preso. Quando saiu da prisão, sentiu-se mal na condição de ex-presidiário, relata que tinha vergonha de sair de casa, o que acarretou em uma depressão - não queria mais comer, só pensava em dormir, etc.

Com o tempo "melhorou" da depressão e foi procurar emprego. No momento da assinatura da carteira de trabalho, o futuro patrão descobriu sua condição de ex-presidiário e não deu prosseguimento aos procedimentos de contratação. Segundo relata, ele foi demitido antes mesmo de ser contratado.
Atualmente ele trabalha em uma pequena empresa de lavagem de carros e realiza trabalhos voluntários em um órgão da prefeitura, como condição para cumprir a pena em liberdade.

\section{Procedimentos da Entrevista}

As conversas livres contribuíram para aproximar pesquisador e participante, mas o objetivo era investigar algumas questões de maneira sistemática, por isso, decidiu-se por formalizar uma entrevista, adotando os seguintes procedimentos: (a) foram esclarecidos os objetivos da pesquisa, introduzida a temática da desigualdade e realizada uma consulta sobre a disponibilidade de participação nesta pesquisa; (b) o participante foi chamado a refletir sobre a temática da desigualdade social, partindo de um relato das suas experiências de vida; (c) foram explicados os procedimentos éticos e a forma como seria analisado aquilo que foi falado (nesse momento, a utilização do gravador foi justificada a partir da necessidade de transcrever a conversa para realizar uma análise sobre o que foi dito). Em conformidade com os termos da lei n. 196/96 (Brasil, 1996), que regulamenta a pesquisa com seres humanos, foi utilizado um termo de consentimento livre e esclarecido, aprovado pelo comitê de ética de pesquisa da universidade.

A entrevista ocorreu na escola onde a filha do participante estuda e durou aproximadamente duas horas. De certa forma, o modelo das questões apresentadas contemplou o objetivo do presente trabalho, que era compreender como ele percebe a desigualdade social na sociedade e em seu cotidiano.

\section{O Formato da Entrevista}

A entrevista foi estruturada a partir de algumas questões norteadoras. Elas foram elaboradas com o objetivo de contemplar o interesse inicial de pesquisa, já explicitado anteriormente. No curso da entrevista, outras questões foram colocadas, respeitando os objetivos da pesquisa. A saber, as questões balizadoras desta entrevista foram: (a) Como a desigualdade social se expressa na sociedade? (b) Como a desigualdade social se expressa em seu cotidiano? (c) Você se identifica com uma classe ou um segmento social e econômico? (d) Por que você acha faz parte deste segmento social? (e) Como se sente vivendo da forma em que vive? (f) Gostaria de viver diferente de como vive atualmente?

A primeira questão permitiu conhecer a visão geral do participante sobre a desigualdade social, o que encaminhou a colocação da segunda questão, permitindo adentrar em elementos da convivência entre ricos e pobres, tendo como referência a relação entre moradores de uma mesma unidade territorial, mas que pertencem a diferentes segmentos sociais. Esse diálogo possibilitou 
a utilização da terceira questão, referente à forma como o participante se caracteriza enquanto membro de um segmento social. A partir de então, outras questões foram direcionadas a fazer refletir sobre a razão das pessoas disporem de condições de vida tão distintas na sociedade em que vivemos. Por último, a entrevista explorou a visão do sujeito sobre as perspectivas futuras de vida.

\section{Resultados e Discussões}

\section{Percepção Sobre a Desigualdade Social: O Olhar de um Jovem em "Apuros"}

A entrevista iniciou-se a partir de uma pergunta: sobre o que, de uma maneira geral, o participante entendia por desigualdade social. Inicialmente, ele destaca que "primeiramente a desigualdade ... tá na discriminação, começando pela cor, pela raça".

A partir dessa observação, fica claro que a questão racial se apresenta, para ele, como uma dimensão da desigualdade social, isto é, a discriminação racial constitui-se como um elemento que torna explícito esse fenômeno.

Outro elemento que, para o participante, caracteriza a desigualdade social é a situação econômica das pessoas. Para ele, a desigualdade social existe "pelo fato de uns serem mais pobre e outros mais ricos". Ele se considera um sujeito pobre, quando diz: "Olha a minha categoria é pobre, vamos se diz assim: categoria. Mas eи num... nem acreditaria ser um rico não".

A diferenciação entre pobreza e riqueza parece estar apoiada pela questão da renda, quando ele coloca que as diferenças entre ricos e pobres podem se dar "pelo fato do dinheiro né! Uma pessoa que ganha trezentos reais por mês e tem que cata na rua pra comer e uma pessoa ganha cinco mil, esbanja... jogar comida fora".

O participante, em alguns momentos, se apoia em estereótipos para caracterizar o sujeito rico. O rico é aquele sujeito que esbanja dinheiro e comida. Mas também existe um elemento concreto que caracteriza o rico: é aquele que possui os bens materiais em abundância.

O contraste entre ricos e pobres fica também claro para o participante quando ele reflete sobre as condições de moradia da população. Assim, considera que a desigualdade social reside também no fato de alguns morarem em condomínio e outros em favelas. Com isso, ele caracteriza o bairro onde vive. Apesar de ser asfaltado e composto por casas de alvenaria e não por barracos, os moradores do bairro não têm a posse do terreno e da casa, vivem em situação de ilegalidade e em condições de vida semelhante a dos moradores de uma favela (Maricato, 2003). Talvez por isso, quando fala do seu bairro, o participante refere-se como sendo uma favela. Assim, o fato de que "alguns moram em condomínios ... e os outros morarem em favela" é um fato que torna a desigualdade social aparente.
A diferenciação entre pobres e ricos pode ser observada pelas distintas condições financeiras e de moradia. Mas por que isso ocorre? Ao ser questionado a respeito das causas da desigualdade social, o participante diz:

Ai a gente vai entrar em um esquema de política, né, de governo, que não dá o mesmo conceito de estudo pra o pessoal pobre da escola pública estadual, do que numa escola particular, que a gente vê muito hoje é que numa escola estadual você, por exemplo, não tem merenda pra todos.

Esta passagem reflete pelo menos dois aspectos importantes da visão do participante sobre a desigualdade social. O primeiro está relacionado ao papel que ele parece atribuir ao governo, para reduzir ou maximizar a desigualdade social. O estado tem a responsabilidade de zelar pela sociedade, todavia, ele parece ser compreendido como uma instância soberana, abstrata, distante da população pobre, "um esquema de política" que não faz parte do esquema do cotidiano. O segundo aspecto é que a crítica relacionada à inoperância do Estado, especificamente à inoperância da escola pública, advém porque esta última é compreendida, em algum grau, como um instrumento que deveria combater a desigualdade social.

Contudo, para ele a desigualdade social não é expressa somente em termos da educação, moradia ou renda. Esse fenômeno se manifesta pela "ética de muitos, que se acham mais que os outros". A partir desta compreensão, podemos nos arriscar a traçar um paralelo entre a ética referida pelo participante (que ele percebe em seu cotidiano) e a moral burguesa, cujo valor de troca impera sobre o valor de uso e a mercadoria torna-se um atributo para se relacionar com o outro (Tonet, 2002). O participante atenta para a questão de uns se acharem mais do que os outros, no sentido de que os ricos, provedores de uma condição financeira mais estável, são indiferentes ou preconceituosos em relação aos pobres, pelo simples fato de eles serem pobres. A ética parece estar relacionada à maneira como os ricos tratam os pobres, assim ele comenta:

A desigualdade é muito grande porque muitos pais de colegas nossos que são ricos não aceita, por exemplo, a nossa presença no ambiente deles. Eles querem ter um cotidiano só pra eles. Não dá pra entender essa desigualdade se todos têm o mesmo direito de conseguir o que quiser.

O rico aparece aqui como o sujeito ativo das relações, aquele que toma a iniciativa em construir um cotidiano próprio, longe da pobreza. É assim que o participante parece compreender as origens da segregação entre ricos e pobres. Mas a diferenciação entre ricos e pobres não constitui uma simples diferenciação econômica. Tal diferenciação reflete um conjunto de relações sociais, um padrão de relacionamento social que se estabelece entre diferentes segmentos sociais. 
A desigualdade social ultrapassa os limites da materialidade e se expressa em todas as esferas da vida humana. É o que o participante observa, não necessariamente porque ele tenha uma percepção aguçada sobre a conjuntura social, mas pelas experiências cotidianas da região onde mora, no local de trabalho, junto às pessoas que convivem, etc. Quando ele fala da ética de "uns se acharam mais do que os outros" ele toma como base, como veremos a seguir, as experiências que vivenciou na sua vida e que, provavelmente, vivencia até os dias de hoje. A convivência entre segmentos sociais distintos é um elemento presente na análise do participante, sendo assim, destacamos a seguir como percebe a relação entre pobres e ricos no âmbito da sua vida cotidiana.

\section{Relação entre Segmentos Sociais Distintos: Uma Reflexão Sobre Experiências da Vida.}

Para o participante, a convivência entre ricos e pobres não é algo evidente somente no seu cotidiano, visto que este fenômeno, na sua avaliação, parece estar presente em toda a sociedade. Assim, destaca que a relação entre diferentes segmentos sociais "Tá no meu dia-a-dia, no seu dia-a-dia, no cotidiano de todos hoje".

Ele reflete sobre a convivência entre ricos e pobres a partir do seu cotidiano. Essa relação entre diferentes segmentos sociais, a forma como ela se dá no seu diaa-dia, ficou expressa de duas maneiras: (a) quando trata da relação patrão $\mathrm{x}$ empregado e (b) da visão preconceituosa da pobreza (o que, para ele, contribui para que os ricos distanciem-se dos pobres).

A convivência entre ricos e pobres pode ser analisada a partir da relação que o patrão estabelece com o empregado. Assim ele apresenta uma situação vivida por sua irmã.

Olha vou dizer pra você assim que teve um caso até com a minha irmã, que a patroa dela disse a ela assim: você pode fazer comida somente para o seu patrão? Então não faça muito! Ela pegou e fez pouca comida... a patroa mandou ela embora porque ela achou que não... que deveria ter feito mais, que na casa dela não tem economia, não precisa economizar. Sendo que só tinha uma pessoa pra comer, pra que fazer mais comida? Se ela fizesse mais, ia jogar fora! Ela fez o tanto exato, que era só pra ele comer. A patroa achou que não. Isso já é um absurdo! Totalmente, é um absurdo!

Quando questionado sobre o que ele considera um absurdo, ele responde: "A pessoa fazer poxa bastante comida pra uma pessoa só, sabendo que vai ter que jogar fora, vai estraga a pessoa não guarda pra janta, porque é uma pessoa rica, que não economiza, isso é... desumano".

O patrão surge, nesse momento, como aquele responsável por dirigir as ordens, por mais injustas que elas sejam. O empregado está subjugado aos mandos do contratante, justamente, porque é ele que está limitado a vender sua força de trabalho.

As relações desumanas do capitalismo estão estreitamente ligadas à questão da privação $\mathrm{x}$ abundância. Tal grau de concentração e desigualdade revela uma situação de progressiva desumanização das relações sociais, em que se torna preferível jogar comida fora a alimentar a empregada. Essa situação, vivenciada pela irmã do participante, certamente é um indicador da intensidade com que a alienação se expressa frente ao outro e ao próprio gênero humano.

Marx (1844/2004a) comenta que a alienação é a marca das relações sociais no capitalismo porque é ela quem determina o padrão de relacionamento mais elementar dessa sociedade: a relação entre empregado e empregador. Dessa forma, Marx chama a atenção para a relação reificada, ou seja, coisificada, inumana em que a maioria absoluta da população é submetida - o trabalhador não é dono de si mesmo, quanto menos dono do processo de trabalho e da riqueza por ele produzida (mesmo no caso da empregada doméstica, que não produz lucro para o patrão, a primeira fica, a priori, subjugada como aquela que só pode contar com sua força de trabalho).

A relação entre patrão e empregado pode ser considerada para o participante, em certa medida, como uma relação desumana. Assim, ele completa: "Eu acho que a riqueza sobe à cabeça do ser humano e transforma ela em uma pessoa desumana, vamos dizer assim". Mas, padaroxalmente, ele segue comentando: "são poucos os ricos que são desumanos". De toda forma, a desumanização das relações é experimentada pelo participante em diferentes esferas da sua vida, também no seu emprego, quando afirma: "Várias vezes eu me senti humilhado". Essa humilhação é sentida no seu dia-a-dia de trabalho, tal como coloca:

Então a gente vê muito isso, que a gente que trabalha nesta área [refere-se à área onde mora], o pessoal vê a gente trabalhando e fala: olha o pobre indo lá trabalhando, o empregado que tadinho. A gente se matando no sábado enquanto o rico ta lá só se divertindo.

A extração da mais-valia (realizada de maneira cada vez mais predatória, porém cada vez mais eficiente do ponto de vista do capital) obriga o trabalhador, independente do seu local de trabalho/emprego, a conviver com situações desagradáveis que geram conflitos, tensões, além da humilhação, problemas emocionais e físicos a que muitos estão submetidos (Aquino, 2007; Crespo \& Lápis, 2007). As recordações que o participante traz sobre o emprego são carregadas de uma emocionalidade que emergem das relações hostis estabelecidas no ambiente de trabalho. Essas relações hostis são, segundo Marx (1844/2004a), oriundas da lógica irracional e antissocial do capitalismo. Atentando superficialmente para essa questão, o participante reflete: "O patrão acha que tem 
mais que o empregado sendo que é o empregado que dá o dinheiro pra ele né!'”. Ele, todavia, não se estende sobre essa questão, que revela uma contradição fundamental do capitalismo, assentada na contradição entre trabalho e capital. O fato é que ele continua avaliando a complexidade da convivência que se estabelece entre pobres e ricos e, nesse sentido, coloca:

Ah, hoje com ... globalização mundial: droga, vício, balada, clubes, bares, o pessoal se mistura um pouco, mas não que os pais aceitem, o pessoal que vem da parte mais alta ... o pessoal quer pegar drogas este tipo de coisa, não igualdade nenhuma. Somente interesse.

O participante identifica uma relação utilitária que o rico pode estabelecer com o pobre, seja na relação entre patrão e empregado, seja por meio da relação comercial da droga, para a satisfação do prazer individual. Aqui o rico aparece mais uma vez como o sujeito ativo da relação: o interesse da relação está fundamentado no interesse do rico em adquirir drogas, por exemplo. Trata-se de um cliente, aquele que, como o patrão, assume a frente das decisões, por ser o proprietário de um comércio ou pela posse de uma quantia significativa de dinheiro.

Ao mesmo tempo em que a desigualdade social assume uma dimensão cada vez mais complexa, esse fenômeno está intrinsecamente ligado à questão da propriedade e da renda. São essencialmente esses os dois fatores fundamentais para diferenciação entre riqueza e pobreza.

O terceiro eixo desta análise revela a maneira como o participante compreende a si mesmo, como caracteriza o sujeito pobre e, consequentemente, como avalia suas perspectivas para o seu futuro.

\section{Visão Sobre o Pobre e Perspectivas Sobre o Futuro}

O participante afirma que "o filho de pobre e o filho de rico têm a mesma condição de chegar a um lugar, ser doutor ou um médico como qualquer outra pessoa". Essa afirmação expressa, de uma maneira ou de outra, uma assimilação da ideologia dominante, à medida que, se o participante compreende que ricos e pobres têm as mesmas condições para se "chegar a um lugar", isso atestaria para a incapacidade de os últimos obterem uma melhor condição de vida (o que denota uma visão fragmentada da pobreza e que, em última instância, centra sua atenção nas questões de ordem estritamente subjetivas, tal como Patto, 1997, discute).

O participante segue argumentando a respeito dessa temática e diz: "Se a pessoa achar que não dá, isso pra mim a própria pessoa já ta discriminando ela mesma".

Se ele aplica alguns estereótipos aos ricos, também tem uma noção estereotipada dos pobres: são aqueles passíveis de serem discriminados. É verdade que o participante pode, com esse argumento, de que os pobres são aqueles que introjetam uma noção de inferioridade, reconhecer a capacidade de o sujeito transcender sua condição imediata de pobreza. Mas até que ponto esta argumentação internalista não se caracteriza como uma argumentação a favor dos ricos? Veja os argumentos que ele encontra, para dizer por que acha que os pobres estão na situação em que se encontram.

Ó, na minha opinião, é a força de vontade, porque muitos pessoas se vê pobre e acha que não vai conseguir, fica sendo humilhado e a pessoa às vezes acaba, a própria pessoa se rebaixa porque escuta de outra pessoa e se sente ofendido e quer correr atrás de seus ideais.

Para ele o fato que torna possível a humilhação (a pobreza) se confunde com o sentimento de humilhação de que, aliás, na sua visão, o pobre parece ser refém. Esse sentimento se justifica, principalmente, como diz Freire (1989), pela excessiva valorização do objeto em detrimento da pessoa humana. De toda maneira, o participante abandona, nesse momento, a crítica realizada anteriormente, em que caracteriza o rico como sendo aquele que humilha os pobres. Essa humilhação passa agora a ser justificada pela própria consciência que o pobre faz de si mesmo, como se a sua condição de pobreza fosse resultado somente desse processo. Trata-se de uma visão internalista, que vê na condição subjetiva a chave para a resolução de todos os problemas de ordem material (Patto, 1997; Martín-Baró, 1980, 1998). Assim, justifica a pobreza não mais pela relação de exploração e pela dominação ideológica que faz o pobre sentir-se inferior ao rico. Para ele, a pobreza é "problema da própria pessoa". Assim, acredita que o pobre "tem que seguir pra frente e ser uma pessoa, um cidadão ideal, vamos dizer assim...".

Perguntamos o que seria um cidadão ideal? Ao que ele responde: "Ah, como já disse antes, correr atrás dos seus ideais, estudar, não importa o que aconteça e é isso ai, procurar seus ideais e não se levar pelos outros".

A ideia de "cidadão ideal" versa sobre um sujeito que supera sua condição de pobreza e, para que isso ocorra, é primordial que o pobre mude a própria consciência que faz de si mesmo. Mas o conceito de "cidadão ideal" para o participante está intimamente ligado à noção de ascensão econômica, o que também não seria de se estranhar, uma vez que ela não representa, necessariamente, um luxo para os pobres, mas antes uma questão de sobrevivência (Eagleton, 1997).

O participante reflete sobre suas perspectivas de futuro quando fala sobre seu ideal de vida: "Bom, currículo eu já não tenho né! [riso] Mas eu queria ser um psicólogo, psicólogo e músico. Esse é meu sonho né! Meu ideal... tem um carro também, ter uma condição melhor de vida". 
Se, por um lado, o participante coloca que a riqueza corrompe o indivíduo, por outro não nega que queira melhorar sua condição de vida. Para o participante, ter uma vida melhor é ter um carro e um currículo para melhor qualificação no mundo do trabalho. Isso, de fato, reflete uma necessidade objetiva e revela uma clareza acerca das tarefas imediatas para se alcançar melhores condições de vida.

O participante tem uma visão lúcida sobre sua condição de vida e sobre as necessidades que estão colocadas para quem se caracteriza como pobre e deseja atingir uma condição digna de vida. $\mathrm{O}$ fato de ele desejar fazer uma faculdade e ter um carro não reflete, por si, uma visão pejorativa dos pobres, tampouco reflete um suposto consumismo. Ser psicólogo, ser músico ou ter um carro revelam a necessidade de o participante alcançar uma vida melhor.

O participante relata que, em muitos casos, se sente inferiorizado na relação com o rico, assim, ele destaca que realmente se "sente constrangido perto das pessoas e às vezes você não consegue nem conversar, fazer uma amizade". Esse constrangimento se expressa "pelo olhar, pelo fato da pessoa passa do seu lado e esnobar você".

Se o participante critica o pobre que se deixa discriminar e que isto seja um fator de vulnerabilidade para assumir uma posição de inferioridade perante os ricos, por outro lado, a esnobação ou a humilhação o incomoda, ora se sente vítima, ora responsável pelo fardo da sobrevivência.

\section{Considerações Finais}

A presente análise dividiu-se em três categorias: (a) definição da desigualdade social, quando o participante definiu o que é esse fenômeno, e o fez com base em suas experiências vividas; (b) relação entre pobres e ricos - aqui ele chama atenção para a ética com que se estabelece essa relação; (c) visão sobre o pobre e perspectivas para o futuro, que é quando ele olha para o pobre como um ser capaz de conquistar um futuro melhor, caso se esforce nesse sentido. Uma vida melhor é compreendida a partir de suas condições de vida, mas o participante não problematiza suas expectativas ao ponto de romper, ideologicamente, com a lógica social que lhe é imposta, e isso ocorre, basicamente, pela ausência de um recorte de classe em suas análises (ele considera o pobre como um ser desprovido de renda e de propriedade, mas não associa essa condição, necessariamente, a uma condição da classe trabalhadora como um todo) (Euzébios Filho, 2007).

Como consequência das reflexões que trazemos aqui, diante do quadro político e econômico que vivemos, chama-nos a atenção a forma como as pessoas reagem às situações desfavoráveis que lhes custam a perda de direitos conquistados e que as conduzem, por exemplo, a uma situação de humilhação. Seria um caminho interessante de investigação estudar a consciência dos sujeitos acerca de suas condições de classe e de vida, assumindo, nessa caminhada, a intenção em analisar os processos psicossociais contra a alienação e o fatalismo.

\section{Notas}

${ }^{1}$ Dissertação de Mestrado intitulada Consciência, ideologia e pobreza: sociabilidade humana e desigualdade social. Este trabalho foi orientado pela professora Dra. Raquel Souza Lobo Guzzo e foi concluído em dezembro de 2007.

2 Para um aprofundamento desta questão, consultar também Costa, 2005; Lessa e Tonet, 2005. o se caracteriza como sendo uma transposiço da filosofia), isto nismo,riamente a divisaos seaçmente nos diferentes per

${ }^{3}$ Aqui passamos rapidamente por dois conceitos centrais: o primeiro, mais elementar, é o trabalho, que representa o intercâmbio orgânico do homem sobre a natureza cuja finalidade é a supressão das necessidades humanas mais básicas, relacionadas à sobrevivência. Por isso, o trabalho é considerado por Marx o elemento fundante da sociabilidade humana. A partir do trabalho se instala um processo de produção social dos meios de vida. O segundo conceito, de autoconstrução do homem pelo homem, trata da mediação consciente que os sujeitos estabelecem com a natureza, com outros sujeitos e com a sociedade. É importante ressaltar, todavia, que esse processo de autoconstrução nem sempre é marcado pela positividade, o que nos obrigaria a debruçar sobre a negatividade "embutida" no conceito de alienação em Marx, que foi discutido por Meszáros (2006).

\section{Referências bibliográficas}

Alfaro, J. I (1993). Elementos para una definición de la Psicología Comunitaria. In R. M. Olave e L. Zambrano (Orgs). Psicología Comunitaria y salud mental en Chile. (pp. 14-31). Santiago: Ed. Universidad Diego Portales.

Aquino, C. A. B. (2007). Transformações no modelo industrial, "novos trabalhos" e novas temporalidades. Psicologia \& Sociedade, 19 (n.spe.), 21-28.

Augoustinos, M. (1999). Ideology, false consciousness and psychology. Teory and Psychology, 9(3), 295 - 312.

Coimbra, C. (2001). Operação Rio: o mito das classes perigosas. Um estudo sobre a violência urbana, a mídia impressa e os discursos de segurança pública. Niterói: Intertexto /Oficina do autor.

Brasil. Conselho Nacional de Saúde. (1996). Lei 196/96, de 10 de outubro de 1996. Diretrizes e normas regulamentadoras de pesquisas envolvendo seres humanos. Acesso em 12 de janeiro, 2009, em http://www.ufrgs.br/bioetica/res19696.htm

Costa, G. M (2005). Trabalho, individualidade e pessoa humana. Tese de Doutorado, Programa de Pós-graduação em Serviço Social, Universidade Federal de Pernambuco.

Crespo, A. R. \& Lápis, N. L. (2007). A saúde e os processos de trabalho no capitalismo contemporâneo: reflexões na interface da sociologia do trabalho e da psicodinâmica do trabalho. Psicologia \& Sociedade, 19(1), 61-68. 
Dobles, I. (1999). Marxism, ideology and psychology. Teory and Psychology, 9(3), $407-410$.

Eagleton, T. (1997). Ideologia (L. C. Borges \& S. Vieira, Trads.). São Paulo: Boitempo.

Euzébios Filho, A. (2007). Consciência, ideologia e pobreza: sociabilidade humana e desigualdade social. Dissertação de Mestrado, Programa de Pós-graduação em Psicologia, Centro de Ciências da Vida, PUC-Campinas.

Euzébios Filho, A. \& Guzzo, R. S. L. (2007). A desigualdade social vista por seus atores. In I. O. Dobles, S. B. Arróliga, \& V. L. Zuñiga (Eds.), Psicología de la liberación en el contexto de la globalización neoliberal (pp. 336-352). San José: UCR.

Freire, P (1989). Pedagogia do oprimido. Rio de Janeiro: Paz e Terra.

García, I., Giuliani, F., \& Wiesenfeld, E. (2002). El lugar de la teoria em psicología social comunitária: comunidad y sentido de comunidad. In M. Montero (Coord.), Psicología social comunitária: teoria, método y experiencia (pp. 75-101). Guadalajara: Universidad de Guadalajara.

González Rey, F. (1998). Lo cualitativo y lo cuantitativo en la investigación de la psicología social. Psicologia \& Sociedade, 9(1-2), 32-52.

González Rey, F. (1999). La investigación cualitativa em psicologia: rumbos y desafios. São Paulo: EDUC.

González Rey, F. (2003). Sujeito e Subjetividade: uma aproximação histórico-cultural (R. S. L. Guzzo, Trad.). São Paulo: Thomsom.

González Rey, F. (2005). Pesquisa qualitativa e subjetividade. Os processos de construção de informação (M. A. F. Silva, Trad.). São Paulo: Thomsom.

González Rey, F. \& Mitjáns, A. M. O. (1989). La personalidad: su educación y desarrollo. Habana: Pueblo y Educación.

Guareschi, P. A. (1996). A ideologia: um terreno minado. Psicologia \& Sociedade, 8(2), 82-94.

Guareschi, P. A. (2005). Psicologia social como prática de libertação. ( $3^{\text {a }}$ ed.). Porto Alegre: Edipucrs.

Guzzo, R. S. L. (2004). Construindo bases para a prevenção primária no Brasil (Relatório Técnico). Brasília: CNPq.

Jacques, M. G. C. (1993). Um método dialético de análise de conteúdo. Revista Psico, 24(2), 117-127.

Konder, L. (1981). O que é dialética? (6 $6^{\mathrm{a}}$ ed.). São Paulo: Brasiliense.

Konder, L. (2003). A dialética e o marxismo. Acesso em 20 de novembro, 2003, em http://www.uff.br/trabalhonecessario/ Konder\%201.htm

Lessa, S. \& Tonet, I. (2004). Introdução à filosofia de Marx. Acesso em 11 de agosto, 2004, em http://www.geocities. com/srglessa

Lowy, M. (1989). Método dialético e teoria política (4a ed., R. Di Piero, Trad.). Rio de Janeiro: Paz e Terra.

Maricato, E. (2003). Metrópole, legislação e desigualdade. Estudos avançados, 17(48), 151-157.

Martín-Baró, I. (1980). Aspiraciones del pequeno burguês salvadoreño. Revista Estudios Centroamericanos, 35(377), $773-788$.

Martín-Baró, I. (1998). El fatalismo como identidad cognitiva. In A. Blanco (Org.), Psicología de la liberación (pp. 39-130). Madri: Trota.

Martín-Baró, I. (2000). Las estructuras sociales y su impacto psicológico. In I. Martín-Baró (Ed), Acción y ideología: Psicología social desde Centroamérica (10ª ed.), (pp. 71-111). San Salvador: UCA Editores.
Marx, K. (2004a). Manuscritos econômico-filosóficos (J. Ranieri, Trad.). São Paulo: Boitempo. (Original publicado em 1844).

Marx. K. (2004b). Teses sobre Feuerbach. In A ideologia alemã (S. D. Chagas, Trad., pp. 121-124). São Paulo: Centauro. (Original publicado em 1845).

Meszáros, I. (2006). A teoria da alienação em Marx (I. Tavares, Trad.). São Paulo: Boitempo.

Oldrini, G. (1995). Lukács e o caminho marxista ao conceito de 'pessoa'. Revista Práxis, (3), 12-25.

Patto, M. H. S. (1993). O conceito de cotidianidade em Agnes Heller e a pesquisa em Educação. Perspectivas, (16), 119-141.

Patto, M. H. S. (1997) Para uma crítica da razão psicométrica. Revista Psicologia USP, 1(8), 47-62.

Séve, L. (1979a). Marxismo e teoria da personalidade. Vol. 1. (E. L. Godinho, Trad.). Lisboa: Horizonte.

Séve, L. (1979b). Marxismo e teoria da personalidade. Vol. 2. (E. L. Godinho, Trad.). Lisboa: Horizonte.

Séve, L. (1979c). Marxismo e teoria da personalidade. Vol. 3. (E. L. Godinho, Trad.). Lisboa: Horizonte.

Tonet, I. (2002). Democracia ou Liberdade? Ijuí: Unijuí.

Tonet, I. (2005). Educação, cidadania e emancipação humana. Ijuí: Unijuí.

Yamamoto, O. H. (1994). Marx e o método. São Paulo: Moraes.

Antonio Euzébios Filho é Doutorando em psicologia pelo programa de pós-graduação da PUC-Campinas.

Bolsista Capes. Atua como psicólogo e pesquisador em comunidades e escolas públicas. Endereço para correspondência: R. Sales de Oliveira, 120. Vila Industrial, apt. 31 - bloco C. Campinas, SP. CEP 13035-270. Email: toninhoeuzebios@hotmail.com

Raquel Souza Lobo Guzzo é Professora titular de psicologia da PUC-Campinas. Coordenadora do projeto "Risco à Proteção: uma intervenção preventiva na comunidade". Endereço para correspondência: R. Santa Mônica, 136. Jardim Santa Marcelina. Campinas, São Paulo. CEP: 13100-101. Email:rguzzo@mpc.com.br

\section{Desigualdade social e pobreza: contexto de vida e de sobrevivência}

Antonio Euzébios Filho e Raquel Souza Lobo Guzzo

Recebido: 08/02/2008

$1^{\text {a }}$. Revisão: $26 / 08 / 2008$

Aceite final: 18/10/2008 